\title{
A COMPARATIVE STUDY OF TRAMADOL AND KETOROLAC FOR PAIN MANAGEMENT IN POST-OPERATIVE PATIENTS WITH APPENDECTOMY
}

\author{
Lujaw Ratna Tuladhar, ${ }^{1}$ Nikhil Acharya, ${ }^{2}$ Shailesh Maharjan ${ }^{2}$
}

${ }^{1}$ Department of Pharmacology and ${ }^{2}$ Department of Surgery, Nepal Medical College and Teaching Hospital (NMCTH), Attarkhel, Gokarneshwor-8, Kathmandu, Nepal

\begin{abstract}
Appendectomy is one of the most common emergency surgical procedures performed in the world. The inflammation of the appendix triggers severe pain in the right lower quadrant of the abdomen. Additionally, the post-operative incision site pain may be distressing to the patients. Analgesic drugs like tramadol (opioid analgesics) and ketorolac (nonsteroidal anti-inflammatory drug - NSAID) are used to manage post-operative pain. The objective was to compare tramadol and ketorolac for pain management by observing the pain-free interval in post-operative patients with appendectomy. A descriptive cross-sectional study was conducted in the department of surgery from November 2019 to May 2020 to observe the duration of pain-free intervals between tramadol and ketorolac. The total number of appendectomy patients selected was 100. Fifty patients received tramadol and the next 50 patients received ketorolac. The data was entered in SPSS and an independent sample t-test was applied to determine the difference in duration of the pain-free interval between ketorolac and tramadol. The average duration of pain-free for the tramadol group was $4.95 \pm 1.19$ hours (4 hours 57 minutes) while for the ketorolac group was $5.24 \pm 1.36$ hours (5 hours 14 minutes). The difference was statistically insignificant. We also observed that the tramadol group (88\%) received more anti-emetic drugs than the ketorolac group (24\%). Therefore, post-operative pain management with ketorolac was found to be as effective as tramadol with comparable duration of the pain free interval.
\end{abstract}

\section{KEYWORDS}

Analgesic, Appendectomy, Effectiveness, Ketorolac, Tramadol

Received on: January 7, 2021

Accepted for publication: May 17, 2021

\section{CORRESPONDING AUTHOR}

Dr. Lujaw Ratna Tuladhar,

Assistant Professor,

Department of Pharmacology,

Nepal Medical College and Teaching Hospital, Attarkhel, Gokarneshwor-8, Kathmandu, Nepal

Email: lujaw3@gmail.com

Orcid No: https://orcid.org/0000-0002-1626-1104

DOI: https://doi.org/10.3126/nmcj.v23i3.40374 


\section{INTRODUCTION}

Pain is a general term that describes uncomfortable sensations in the body. The origin of all pain is inflammation and inflammatory response. ${ }^{1}$ Current trend on pain management includes medications like nonsteroidal anti-inflammatory drugs (NSAID) and opioids analgesics. ${ }^{1}$ Ketorolac is a member of a class of drugs called NSAIDs. It is more effective than other NSAIDs. ${ }^{2}$ Ketorolac does not bind to opioid receptors and accordingly lacks many of the side effects typically associated with opioids. ${ }^{3,4}$ Tramadol is an opioid analgesic. It works by binding to the $\mu$-opioid receptor. Tramadol lacks gastrointestinal, cardiovascular and renal toxicities typically associated with ketorolac. ${ }^{4}$

Various studies have compared ketorolac and tramadol but have not reported superior

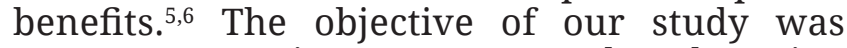
to compare pain management by observing the pain-free interval between tramadol and ketorolac in post-operative patients with appendectomy. An appendectomy is the surgical removal of the vermiform appendix due to appendicitis. ${ }^{7,8}$ The life time risk for appendicitis is $7 \%$ and its prevalence varies from $4.9 \%-8.6 \% .^{9,10}$

\section{MATERIALS AND METHODS}

It was a hospital-based cross-sectional study. The study was conducted from November 2019 to May 2020 in the surgery ward of Nepal Medical College and Teaching Hospital (NMCTH), Kathmandu, Nepal. In our study, we had taken 100 patients as our sample size. Patients were selected based on systematic random sampling. The data were collected through a questionnaire that included details of patient information, an analgesic used and a visual analog scale. Ethical approval was taken from the Institutional Review Committee (IRC) of NMCTH and written consent was taken from every patient before the study. Patients who underwent open appendectomy for appendicitis and understood visual analog scale- VAS (capable of expressing their pain in terms of the scale) were enrolled for the study. Patients allergic to or with a history of an adverse drug reaction to tramadol and ketorolac were excluded from the study. Patients with impaired renal function and/or liver function disorders, unable to communicate and using analgesic combination were also excluded from this study. Patients were divided into 2 equal groups (group A: Tramadol; group B: Ketorolac).

Group A (50 patients) - Tramadol 50mg intravenous

Group B (50 patients) - Ketorolac 30 mg intravenous

The analgesics were given on a "when required" basis. After the patients were transferred to the surgery ward, the time frame between the first and second dose of analgesics was noted on the questionnaire. The first and second dose of analgesic was given when patient complained of distressing pain (VAS score 5). The data collected was entered and processed with SPSS 16 software for Windows. An independent sample t-test was used to determine the difference in duration of the pain-free interval between ketorolac and tramadol. The frequency of use of anti-emetic drugs was compared between the two groups using the chi-square test.

\section{RESULTS}

The average duration of pain-free interval for the tramadol group was $4.95 \pm 1.19$ hours ( 4 hours 57 minutes) and for the Ketorolac group was $5.24 \pm 1.36$ hours (5 hours 14 minutes). Although there was a difference in their mean duration of the pain-free interval between ketorolac and tramadol, this difference was not statistically significant. The difference in their mean duration of the pain-free interval was only 17 minutes. Therefore, In our study tramadol and ketorolac had a similar duration of the painfree interval in post appendectomy patients. We also observed that the tramadol group received more anti-emetic drugs compared to the ketorolac group. Eighty-eight percent of the patient on tramadol received antiemetic drugs whereas only $24 \%$ of the patient on ketorolac received anti-emetic drugs which were found to be statistically significant $(\mathrm{p}<0.001)$.

\section{Table 1: Independent sample t-test applied for duration of pain free interval among} Tramadol and Ketorolac group.

\begin{tabular}{lllll} 
Drug & No. of patients & \multicolumn{2}{l}{ Duration of pain free interval } & p value \\
& & Mean & Standard deviation & \\
Tramadol & 50 & 4.95 & 1.19 & $\mathrm{p}>0.05$ \\
Ketorolac & 50 & 5.24 & 1.36 & \\
\hline
\end{tabular}


Table 2: Chi square test applied to observe pattern of anti-emetic drug used in Ketorolac and Tramadol group.

\begin{tabular}{lccc|} 
Drug & \multicolumn{2}{c}{ Anti-emetic drug use } & Total \\
& Yes & No & \\
Ketorolac & 12 & 38 & 50 \\
Tramadol & 44 & 6 & 50 \\
\hline
\end{tabular}

\section{DISCUSSION}

The comparison between the two drugs is generally associated with their safety and efficacy. Ketorolac and tramadol both have a long history of safety and efficacy. Although both of them are generally used for the management of moderate to severe pain, there is a considerable difference in their pharmacokinetic and pharmacodynamic profile.

Tramadol belongs to class opioids analgesics, is one of the most common opioid analgesics used for the management of moderate to severe pain. The duration of the action of tramadol is around nine hours. Ketorolac belongs to class NSAID and is one of the most common NSAID analgesics used for moderate to severe pain. The duration of action of ketorolac is around 4-6 hours. Although there is a difference in the duration of pain-free interval for tramadol ( 9 hours) and ketorolac (4-6 hours), we found that the duration of pain-free interval for tramadol and ketorolac did not significantly differ in clinical practice. Therefore, pain control with ketorolac was similar to that of tramadol which explains the equivalent effectiveness of the drug. But some studies have concluded tramadol to have better pain control than ketorolac. ${ }^{11}$ Tramadol has better pain control in oral and maxillofacial surgery, ${ }^{11}$ orthognathic surgery, ${ }^{12}$ third molar surgery, ${ }^{13}$ orthopedic and traumatologic postoperative pain, ${ }^{14}$ nasal surgery, ${ }^{15}$ laparoscopic surgery ${ }^{16}$ and pediatric inguinal herniotomy. ${ }^{17}$ Lee $\mathrm{H}$ et al in his study concluded that tramadol with paracetamol combination is as effective as ketorolac with paracetamol combination. ${ }^{18}$ Other studies that concluded ketorolac to be as effective as tramadol were regarding maxillofacial surgery, ${ }^{19}$ abdominal surgery. ${ }^{20}$

Although we observed both the drugs were having a similar duration of the pain-free interval which proves their effectiveness in pain management, our next concern was safety. Studies have shown that ketorolac to be comparatively safer than tramadol. We did not observe any significant adverse drug reaction with both the drugs but the use of the anti-emetic drug along with tramadol was more significant than for ketorolac. Our observation showed anti-emetic drugs were prescribed more for the tramadol group than for the ketorolac group. Eighty-eight percent of the patients on tramadol were prescribed antiemetic drugs whereas only $24 \%$ of the patients on ketorolac were prescribed anti-emetics. The mechanism behind vomiting due to tramadol could be due to stimulation of the opioid receptor in the chemoreceptor trigger zone in the human brain leading to vomiting. ${ }^{21}$ Studies have also concluded that tramadol induces vomiting. ${ }^{22}$ The common gastrointestinal adverse drug reactions of tramadol were nausea in $7.4 \%$ and vomiting in $9.6 \%{ }^{23}$ which explains why anti-emetic drugs were required. On the other hand, ketorolac has proved to reduce the incidence of nausea and vomiting when used in place of opioids. ${ }^{24}$ Although the study showed a reduced incidence of vomiting with ketorolac, we observed that $24 \%$ were prescribed anti-emetic drugs which could be to avoid postoperative nausea and vomiting. ${ }^{25}$ If both the drug have similar pain-free intervals then the use of ketorolac can avoid concomitant use of the antiemetic drug as well as the associated adverse drug reaction observed with tramadol. Therefore, post-operative pain management with ketorolac was found to be as effective as tramadol with a comparable duration of the pain-free interval. However, larger studies with larger sample size may be required.

Conflict of interest: None

Source of research fund: None

\section{REFERENCES}

1. Hush JM, Nicholas M, Dean CM. Embedding the IASP pain curriculum into a 3-year pre-licensure physical therapy program. PAIN Reports 2018; 3: 645-8. Available from: http://insights.ovid. comssref?an=01938936-201804000-00007
2. White PF, Raeder J, Kehlet H. Ketorolac. Anesth Analg 2012; 114: 250-4. Available from: http:// journals.lww.com/00000539-201202000-00002

3. Shrestha L, Joshi B, Palikhey A, Bhattarai K. Comparative Study on Efficacy of Ketorolac and Pethidine for Postoperative Pain Management.J Univ Coll Med Sci 2019; 7: 27-32. Available from: 
https://www.nepjol.info/index.php/JUCMS/ article/view/24682

4. Uribe AA, Arbona FL, Flanigan DC, Kaeding CC, Palettas M, Bergese SD. Comparing the Efficacy of IV Ibuprofen and Ketorolac in the Management of Postoperative Pain Following Arthroscopic Knee Surgery. A Randomized Double-Blind Active Comparator Pilot Study. Front Surg 2018; 5: 1-10. Available from: https://www.frontiersin. org/article/10.3389/fsurg.2018.00059/full

5. Martins LD, Rezende M, Loguercio AD, Bortoluzzi MC, Reis A. Analgesic efficacy of Ketorolac associated with a tramadol/acetaminophen combination after third molar surgery - a randomized, triple-blind clinical trial. Med Oral Patol Oral y Cir Bucal 2019; 24: e96-102. Available from: https://pubmed.ncbi.nlm.nih. gov/30573715/

6. Lepri A, Sia S, Catinelli S, Casali R, Novelli G. Patient-controlled analgesia con tramadolo versus tramadolo plus ketorolac. Minerva Anestesiol 2006; 72: 59-67. Available from: https://pubmed.ncbi.nlm.nih.gov/16407807/

7. Hughes MJ, Harrison E, Paterson-Brown S. Post-operative antibiotics after appendectomy and post-operative abscess development: a retrospective analysis. Surg Infect (Larchmt). 2013; 14: 56-61. Available from: http://www. ncbi.nlm.nih.gov/pubmed/23427791

8. Flum DR. Acute Appendicitis- Appendectomy or the "Antibiotics First" Strategy. Solomon CG, editor. NEngl JMed 2015; 372: 1937-43. Available from: NEJMcp1215006

9. Shrestha R, RanabhatS, TiwariM. Histopathologic analysis of appendectomy specimens. J Pathol Nepal 1970; 2: 215-9.

10. Upadhyaya P, Agarwal CS, Karak AK, Karki S, Pradhan A, Subba TN. Prevalence of Histologically Proven Acute Appendicitis and Incidental Carcinoid Tumour in the Practice of Surgical Pathology at BPKIHS. J BP Koirala Inst Health Sci 2018; 1: 73-80.

11. Shankariah M, Mishra M, Kamath RAD. Tramadol Versus Ketorolac in the Treatment of Postoperative Pain Following Maxillofacial Surgery. J Maxillofac Oral Surg 2012; 11: 264-70. Available from: http://link.springer. com/10.1007/s12663-011-0321-y

12. Gecaj-Gashi A, Nikolova Z, Uka S, Bruqi B, Krasniqi I, Hashimi M. Efficacy of ketorolac vs. tramadol in the treatment of postoperative pain in orthognatic surgery. Eur J Anaesthesiol 2013; 30: 220-3. Available from: https://journals.lww. com/ejanaesthesiology/Fulltext/2013/06001/ Efficacy_of_ketorolac_vs_tramadol_in_the.689. aspx

13. Isiordia-Espinoza M, Pozos-Guillen A, MartinezRider R, Perez-Urizar J. Comparison of the analgesic efficacy of oral ketorolac versus intramuscular tramadol after third molar surgery: A parallel, double-blind, randomized, placebo-controlled clinical trial. Med Oral Patol Oral Cir Bucal 2016; 21: e637-43. Available from: http://www.medicinaoral.com/medoralfree01/ aop/21077.pdf

14. Lanzetta A, Vizzardi M, Letizia G et al. Intramuscular tramadol versus ketorolac in patients with orthopedic and traumatologic postoperative pain: a comparative multicenter trial. Curr Ther Res 1998; 59: 39-47. Available from: https://linkinghub.elsevier.com/retrieve/ pii/S0011393X98850224

15. Colletti V, Carner M, Vincenzi A et al. Intramuscular tramadol versus ketorolac in the treatment of pain following nasal surgery: a controlled multicenter trial. Curr Ther Res 1998; 59: 608-18. Available from: https://linkinghub. elsevier.com/retrieve/pii/S0011393X98850595

16. Putland AJ, McCluskey A. The analgesic efficacy of tramadol versus ketorolac in day-case laparoscopic sterilisation. Anaesthesia 1999; 54: 382-5. Available from: http://doi.wiley. com/10.1046/j.1365-2044.1999.00739.x

17. El Deeb A, El-Morsy GZ. Comparison of preemptive analgesic effect of intravenous ketorolac versus tramadol in pediatric inguinal herniotomy: A randomized double blind study. Egypt J Anaesth 2011; 27: 207-11. Available from: https://www.tandfonline.com/doi/full/10.1016/j. egja.2011.07.005

18. Lee H, Ting S, Lau FA. Randomised Control Trial Comparing the Efficacy of Tramadol and Paracetamol against Ketorolac and Paracetamol in the Management of Musculoskeletal Pain in the Emergency Department. Hong Kong J Emerg Med 2008; 15: 5-11. Available from: http://journals. sagepub.com/doi/10.1177/102490790801500102

19. Zackova M, Taddei S, Calò P, Bellocchio A, Zanello M. Ketorolac vs tramadol in the treatment of postoperative pain during maxillofacial surgery. Minerva Anestesiol 2001; 67: 641-6.

20. Hendarman I, Triratna S, Kamaludin M, Theodorus T. Ketorolac vs. tramadol for pain management after abdominal surgery in children. Paediatr Indones 2014; 54: 118-20. Available from: https://paediatricaindonesiana. org/index.php/paediatrica-indonesiana/article/ view/390

21. Kim E, Choi C-B, Kang C, Bae S-C. Adverse events in analgesic treatment with tramadol associated with CYP2D6 extensive-metaboliser and OPRM1 high-expression variants. Ann Rheum Dis 2010; 69: 1889-90. Available from: http://ard.bmj.com/ cgi/doi/10.1136/ard.2009.124347

22. Montastruc F, Benevent J, Chebane L et al. Vomiting and constipation associated with tramadol and codeine: a comparative study in VigiBase®. Eur J Clin Pharmacol 2018; 74: 1673-4. Available from: http://link.springer. com/10.1007/s00228-018-2536-Z

23. Moulis F, Rousseau V, Abadie D et al. Serious Adverse Drug Reactions With Tramadol Reported to the French Pharmacovigilance Database Between 2011 and 2015. Therapies 2017; 72: 61524. Available from: https://linkinghub.elsevier. com/retrieve/pii/S0040595717300884

24. Hough MP, Waugaman WR. Ketorolac and propofol administration for prevention of nausea and vomiting in patients undergoing minor gynecologic surgery. Nurse Anesth. 1993; 4: 9-17.

25. Munro HM, Riegger LQ, Reynolds PI. Comparison of the analgesic and emetic properties of ketorolac and morphine for paediatric outpatient strabismus surgery. Br J Anaesth 1994; 72: 624-8. Available from: https://linkinghub.elsevier.com/ retrieve/pii/S0007091217444254. 